\title{
Studi Keterdapatan Unsur Tanah Jarang REE Ce dan Y pada Berbagai Kolong di Pulau Bangka
}

\section{(The Study of Rare Elements Ce and Y from Some Kolong in Bangka Island)}

\author{
Irvani $^{1}$ Janiar Pitulima ${ }^{1}$ \\ ${ }^{1} J u r u s a n$ Teknik Pertambangan Universitas Bangka Belitung
}

\begin{abstract}
Rare earth element REE is very potential future prospect mineral resources in Bangka Island, hence a well developed REE must have a high economic value in the future. As one of the biggest region that producing tin ore mining (cassiterite) for hundreds of years, REE potential not yet explored and exploited well until now days in Bangka Island, and was left abundant in ex-mining area. They carried out from the tin ore mining and become mine waste or tailing and then through the stream flows to be suspension or bed load sediment. The aim of this study is to identify the present rare earth Ce and $Y$ based on shallow surface sediment samples and their spatial distribution from a number of mine ponds called kolong. Primary data collection of shallow surface sediments has been collected on Kolong Argotirto and Menjelang West Bangka District, Kolong PLN and Merawang in Bangka District, Kolong Rentensi Kacang Pedang and Pedindang in Pangkalpinang City. Geochemical sediments analysis just for identification the presence of rare earth $\mathrm{Ce}$ and $Y$. Rare earth element of cerium (Ce) just presence in a few sample sediment, but for yittrium $(Y)$ almost presence at all shallow surface sediment 0,9-31,6 ppm. The spatial distribution of rare earth $\mathrm{Ce}$ and $Y$ show heterogeneity in laterally.
\end{abstract}

Keywords : kolong, rare earth

\section{Pendahuluan}

Pulau Bangka memiliki morfologi yang relatif datar sejauh mata memandang, yang dinyatakan sebagai Sunda Peneplain oleh Van Bemmelen (1970). Pada beberapa lokasi terdapat bukit-bukit dari batuan beku asam granit secara setempatsetempat. Sebagai bagian dari Paparan Sunda (Sunda-Shelf) yang stabil, Pulau Bangka merupakan pulau terbesar dari paparan. Aktivitas kegempaan atau seismik sangat jarang tercatat di Pulau Bangka. Posisi geologi Pulau Bangka disebutkan oleh Barber et al. (2005) terletak pada inti benua dari Sundaland Craton Lempeng Eurasia, sehingga merupakan bagian benua yang stabil.

Kehadiran mineral cassiterite di Pulau Bangka sangatlah melimpah dan telah ditambang selama ratusan tahun lamanya, termasuk mineral ikutannya yang memiliki nilai ekonomis yang jauh lebih tinggi jika mampu ditambang, diolah dan dipasarkan. Mineral ikutan mengandung kekayaan unsur-unsur berharga yang tidak lepas dari keberadaan Pulau Bangka yang terletak pada Sabuk Timah Asia Tenggara (Cobbing, 2005). Berbagai mineral yang terikut

* Korespondensi Penulis: (Irvani) Jurusan Teknik Pertambangan Universitas Bangka Belitung, Kawasan Kampus Terpadu UBB Kecamatan Merawang Kabupaten Bangka.

Email: bujangbabel@yahoo.co.id dalam penambangan bijih timah cassiterite berupa kuarsa, pyrite, zirkon, rutile, ilmenite, xenotime dan monazite (Sujitno, 2015). Pada mineral ikutan tersebut terdapat berbagai unsur yang berharga dengan nilai ekonomis yang sangat tinggi seperti $\mathrm{Ce}$ dan $\mathrm{Y}$ yang terdapat pada mineral ilmenite, rutile, monazite dan xenotime.

Mineral ikutan dengan potensi yang sangat besar, terutama untuk unsur tanah jarang pada penambangan bijih timah cassiterite belum dieksplorasi dan dieksploitasi secara terencana. Ekplorasi dan eksploitasi belum sampai tahap menjadikan mineral ikutan tersebut sebagai mineral utama. Data yang diperoleh baru sebatas pencatatan sebagai mineral ikutan pada penambangan bijih timah. Hasil olahan pada pencucian mineral ikutan baru sebatas sebagai produk sampingan dalam skala yang kecil dan jauh dari ideal jumlahnya jika ditujukan untuk kegiatan yang bersifat komersil.

Oleh karena itu salah satu hal yang sangat penting untuk dilakukan saat sekarang ini adalah mengiventarisir kehadiran mineral ikutan tersebut dan menjadikannya sebagai mineral utama dalam sasaran kegiatan eksplorasi. Dalam penelitian ini dimaksudkan sebagai studi pendahuluan untuk mendapatkan gambaran secara umum kehadiran unsur penting (Rare Earth Element/REE) Ce dan Y di berbagai kolong di Pulau Bangka. 


\section{Lokasi Penelitian}

Penelitian dilakukan pada beberapa kolong yang terdapat di Pulau Bangka yang terdapat di Kecamatan Muntok Kabupaten Bangka Barat, Kecamatan Sungailiat Kabupaten Bangka dan
Kota Pangkalpinang. Gambar 1 merupakan peta yang menunjukkan posisi relatif lokasi penetian. Secara umum kolong yang dijadikan temat pengambilan perconto sedimen merupakan kolong yang berumur tua yang merupakan eks lokasi penambangan bijih timah.

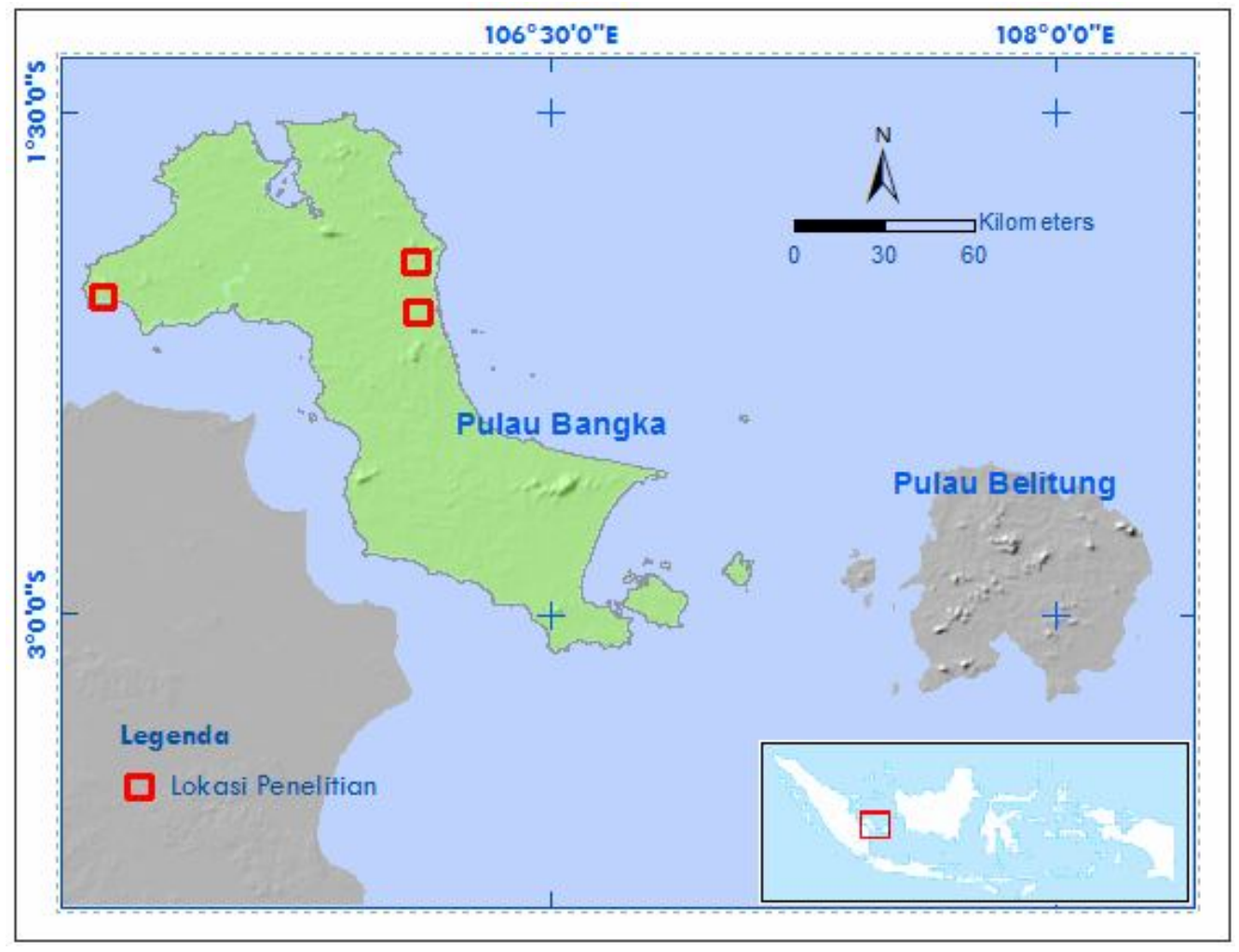

Gambar 1. Peta sebaran lokasi penelitian

\section{Tinjauan Pustaka}

\section{Geologi Pulau Bangka}

Berdasarkan Mangga \& Djamal (1994) dan Margono dkk (1995) secara berurutan telah memetakan batuan tertua di Pulau Bangka diwakili oleh Kompleks Malihan Pemali yang berumur Karbon-Perm, diikuti oleh Diabas Menyabung berumur Perm-Trias, batuan Formasi Tanjung Genting berumur Trias, batuan beku Granit Klabat berumur Trias-Jura, Formasi Ranggam berumur Kuarter dan endapan lepas Aluvial sebagai endapan yang paling muda berumur Tersier. Batuan Kompleks Malihan Pemali disusun oleh batuan metamorf atau malihan yang terdiri dari filit dan sekis.

Batuan beku dengan tekstur diabasik, berupa Diabas Penyabung pada saat Perm-Trias mengintrusi atau menerobos Kompleks Malihan Pemali, yang dapat dijumpai singkapannya di Bukit Penyabung Kabupaten Bangka Barat (Mangga \& Djamal, 1994 dan Ko, 1986). Selanjutnya pengendapan batuan sedimen pada lingkungan laut dangkal terjadi sewaktu Trias membentuk batuan Formasi Tanjung Genting.
Batuannya terdiri dari perselingan batupasir malihan, batupasir, batupasir lempungan dan batulempung dengan lensa batugamping, berlapis baik dan terlipatkan kuat, terkekarkan dan tersesarkan.

Pada Trias-Jura terjadi intrusi batuan beku dengan komposisi asam Granit Klabat yang menerobos ketiga formasi batuan di atasnya. Batuan beku granit periode magmatik yang paling muda merupakan Tin Granite yang membentuk bukit sisa erosi (Katili, 1967). Tin Granite merupakan batuan beku asam yang membawa timah. Tipe batuannya terdiri dari granit, granodiorit, adamalit, diorit dan diorit kuarsa, secara setempat-setempat dijumpai retas aplit dan pegmatit.

Secara tidak selaras pada Miosen Akhir Pleistosen pada lingkungan Fluviatil sampai peralihan diendapkan batuan Formasi Ranggam yang terdiri dari perselingan batupasir, batulempung dan batulempung tufaan, dengan ciri-ciri batuan dapat diremas, serta mengandung bijih timah sekunder pada lapisan batupasir kuarsa. Pada Kala Holosen mulai terbentuk endapan lepas, yang kemudian disebutkan oleh 
Aleva (1985) berhubungan dengan sistem placer cassiterite. Endapannya terdiri dari material lempung, pasir, kerikil, kerakal dan bongkah.

\section{Tinjauan Unsur Tanah Jarang (REE)}

Negara Cina diikuti oleh Negara Amerika dan Australia merupakan negara-negara penghasil unsur-unsur tanah jarang (Rare Earth Element/REE) terbesar dan terkemuka di dunia, termasuk Negara India, Brazil, Kyrgistan, Rusia, Malaysia dan Negara Thailand. REE terdiri dari 15 unsur Lantanida dan Yttrium, dimana REE dikelompokkan kedalam REE ringan yang memiliki nomor atom 57-63, sedangkan REE berat memiliki nomor atom 64-71, kecuali Yttrium yang memiliki nomor atom 39 (Castor and Hendrick, 2006). REE secara geologi berhubungan dengan cebakan REE-besi, cebakan karbonatit, laterit, placer, peralkaline batuan beku, urat-urat, dan cebakan lainnya seperti pegmatit dan akumulasinya pada batuan sedimen (Castor and Hendrick, 2006, Krahulec, 2011 dan McLemore, 2012).

Rodriguez et al. (2013) meneliti pola unsurunsur tanah jarang (REE) pada sistem fluvial yang berhubungan dengan penambangan emas, dimana menunjukkan bahwa konsentrasi REE jauh lebih tinggi djumpai pada endapan sedimen permukaan hasil pelapukan batuan, sedangkan pada tailing dan abu pada lokasi penambangan diidentifikasi dalam jumlah yang lebih rendah.
Jika dikaitkan dengan kondisi geologi Pulau Bangka yang banyak ditutupi oleh endapan Aluvial sebagaimana yang dikemukakan oleh Mangga \& Djamal (1994) dan Margono dkk (1995), maka kehadiran REE diperkirakan akan berlimpah dan berhubungan dengan sistem placer cassiterite (Aleva, 1975).

Pola sebaran REE secara spatial dijumpai membentuk pola yang heterogen. Pola heterogenitas didapatkan baik pada pelamparan lateral maupun longitudinal pada endapan sedimen estuari yang berbutir halus (Hannigan et al., 2010). Adapun untuk detritus endapan sedimen yang terdapat pada daerah pantai secara dominan mengandung REE yang lebih berat, sedangkan dalam detritus sedimen berbutir halus pada daerah paparan menunjukkan adanya pengayaan mineral yang mengandung REE berkategori ringan (Jayaprakash et al., 2016).

Demikian juga terhadap hasil analisis perconto tanah dan endapan sedimen yang berasal dari sekitar area eks penambangan mengandung sejumlah besar mineral seperti monasit, ilmenit dan zirkon. Pemisahan logamlogam tersebut dapat dilakukan melalui proses basah yang kemudian dilanjutkan menggunakan megnetik separator, dimana mineral tersebut mengandung sejumlah unsur logam tanah jarang (REE) (Hamzah et al., 2009).

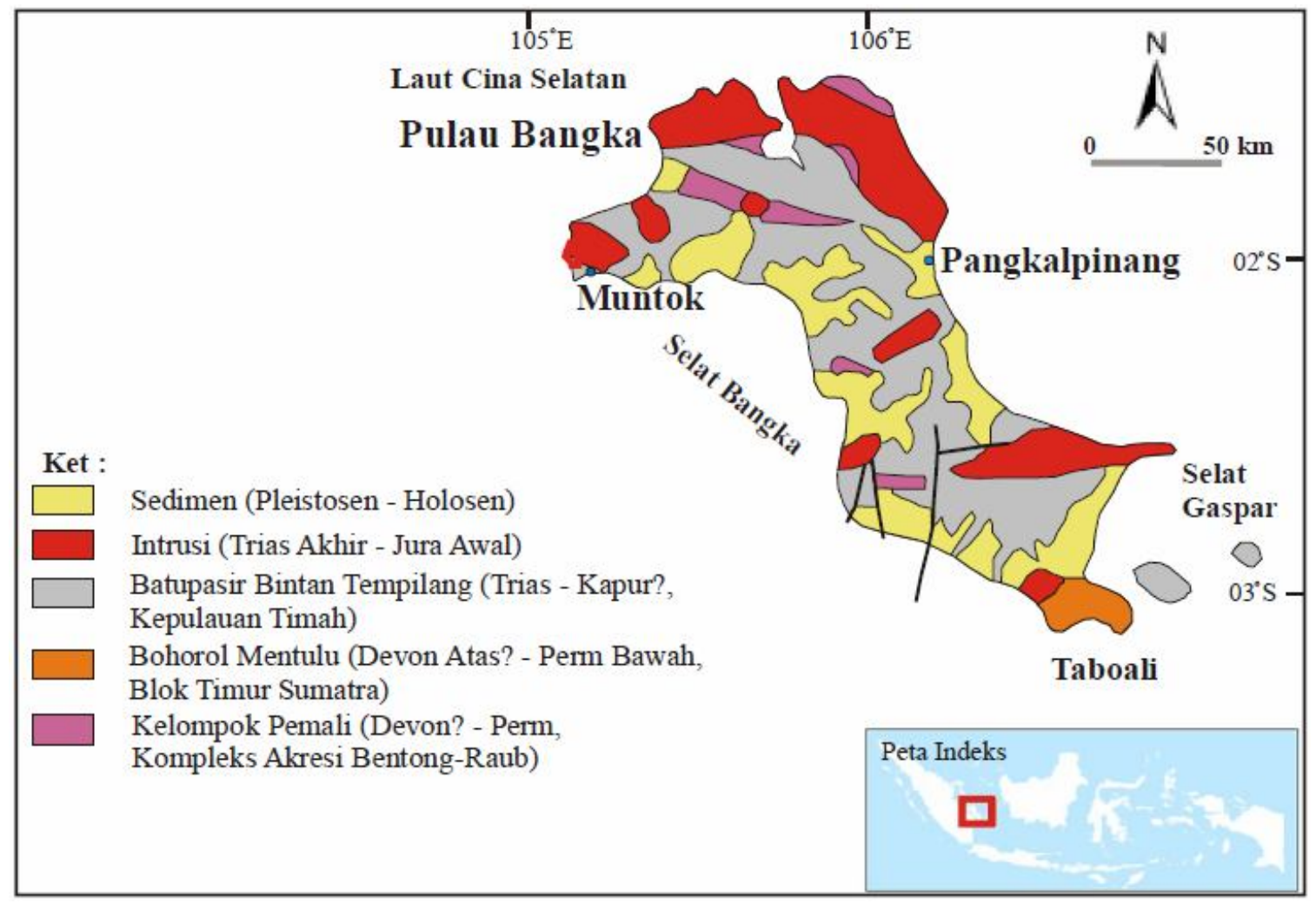

Gambar 1. Simplifikasi peta geologi regional Pulau Bangka (Crow \& Barber, 2005) 


\section{Metode Penelitian}

Lokasi penelitian terdapat pada kolongkolong yang tersebar di Kabupaten Bangka Barat, Kabupaten Bangka dan Kota Pangkalpinang. Kolong-kolong tersebut umumnya merupakan eks lokasi penambangan bijih timah pada masa lampau yang telah berumur tua dan dimanfaatkan sebagai sumber air baku. Sebanyak 10 (sepuluh) perconto sedimen diambil dari 6 (enam) kolong yang tersebar di beberapa tempat yang terpisahkan jauh satu sama lain.

Tahapan penelitian meliputi tahap persiapan, survey tinjau lokasi atau reconnaissance, pengambilan data primer, pengayaan data sekunder serta analisis laboratorium terhadap perconto sedimen. Adapun detail tahapan penelitian terhadap identifikasi unsur Ti, Ce dan Y meliputi :

1) Observasi terhadap lokasi penelitian, termasuk proses perizinan,

2) Pengumpulan data primer di lapangan dengan pengambilan perconto sedimen pada bagian dasar kolong,

3) Analisis laboratorium dengan menggunakan XRF untuk mengidentifikasi kadar unsurunsur Ti, Ce dan Y,

4) Interpretasi data hasil analisis laboratorium.

Pada setiap titik pengambilan data sediment dilakukan pencatatan posisi geografis menggunakan GPS (Global Possitioning System) termasuk kedalaman kolom air.

\section{Hasil dan Pembahasan}

Perconto sedimen diambil dari berbagai kolong lokasi studi di Pulau Bangka yang secara umum merupakan eks lokasi penambangan bijih timah atau telah dipengaruhi oleh aliran sungai masuk ke dalam kolong yang diamati mengandung sejumlah muatan suspensi tailing penambangan bijih timah cassiterite. Sebagai kolong yang telah dimanfaat sebagai sumber air baku, kolong-kolong tersebut telah berumur tua dan dinilai layak sebagi sumber air baku untuk memenuhi kebutuhan masyarakat.

Kolong Argotirto bukan merupakan kolong eks penambangan timah yang aktif, akan tetapi dalam aliran sungai yang masuk ke dalam kolong diperkirakan telah tercemar oleh limbah tailing dari hasil penambangan mineral cassiterite skala kecil (tambang timah inkonvensional/TI) yang terdapat di bagian hulu sungai. Sedangkan untuk Kolong Menjelang merupakan eks lokasi penambangan cassiterite dan sampai saat penelitian dilakukan masih dijumpai kegiatan penambangan di sekitar kolong, sehingga sangat dimungkinkan limbah tailing penambangan dapat masuk mengikuti aliran air ke dalam kolong.
Demikian halnya dengan Kolong PLN dan Merawang Kabupaten Bangka serta Kolong Rentensi Kacang Pedang dan Kolong Pedindang Kota Pangkalpinang yang juga menunjukkan adanya aktivitas penambangan bijih timah skala kecil yang terdapat di bagian aliran sungai yang masuk ke dalam kolong. Secara khusus teridentifikasi di lapangan terdapat aktivitas penambangan bijih timah yang masih cukup banyak dilakukan oleh masyarakat sekitar, yang dikenal sebagai tambang inkonvensional (TI) di bagian hulu sungai yang merupakan sumber air dari Kolong Pedindang. Kegiatan penambangan tersebut mengakibatkan pencemaran tailing yang dapat masuk ke dalam kolong melalui aliran sungai yang masuk ke dalam kolong.

Berdasarkan fokus tujuan utama studi yang secara khusus mengenai unsur penting tanah jarang (REE) untuk unsur serium (Ce) dan yittrium $(Y)$ yang terdapat di dalam endapan sedimen pada berbagai kolong, menunjukkan kadar yang beragam dalam satuan ppm untuk setiap perconto yang dianalisis. Tabel 1 secara detail menunjukkan jumlah (ppm) unsur Ce dan Y. Teridentifikasi bahwa kehadiran unsur REE Ce dan $Y$ tidak dijumpai pada semua perconto sedimen yang dianalisis.

Pada sedimen permukaan kolong unsur $\mathrm{Ce}$ secara umum tidak dijumpai, dimana unsur Ce hanya dijumpai pada Kolong Merawang sebesar 1090,6 ppm dan aliran sungai masuk ke Kolong Retensi Kacang Pedang sebesar 119,5 ppm. Unsur tanah jarang (REE) Y ditemukan hampir pada semua sedimen kolong, kecuali pada aliran sungai masuk ke Kolong Merawang, sedimen Kolong Pedindang dan Kolong Retensi Kacang Pedang. Kandungan unsur $Y$ dalam endapan sedimen berkisar antara 0,9 ppm pada Kolong Merawang Bangka sampai dengan tertinggi sebesar 31,6 ppm pada aliran sungai masuk ke Kolong Retensi Kacang Pedang.

Sebaran unsur tanah jarang (REE) Ce tidak sama dengan unsur $Y$, menunjukkan distribusi mineral pembawa REE tidak terdistribusi secara merata walaupun berasal dari sumber batuan pelapukan batuan atau endapan sedimen yang sama. Pada berbagai kolong yang sama dengan lokasi tempat pengambilan perconto yang berbeda menunjukkan keterdapatan unsur $\mathrm{Ce}$ dan $\mathrm{Y}$ yang berbeda pula dengan unsur $\mathrm{Ce}$ umumnya tidak hadir pada semua perconto.

Dapat diperkirakan bahwa sebaran spatial lateral dan vertikal mineral-mineral pembawa REE yang bersosiasi dengan mineral cassiterite adalah tidak merata, walaupun pada kolong yang sama. Pola yang tidak merata dipengaruhi oleh pola sedimentasi yang terjadi pada kolong yang dipengaruhi oleh kondisi geologi dan proses pengangkutan endapan sedimen. Pola ini juga telah diidentifikasi oleh Hannigan et al. (2010). 
Tabel 1. Data analisis kuantitatif sedimen pada kolong

\begin{tabular}{clcc}
\hline \hline No & Kolong & $\begin{array}{c}\text { Ce } \\
\mathrm{ppm}\end{array}$ & $\begin{array}{c}\mathrm{Y} \\
\mathrm{ppm}\end{array}$ \\
\hline 1 & Argotirto Muntok Bangka Barat & - & 24,9 \\
2 & Menjelang Muntok Bangka Barat & - & 21,1 \\
3 & PLN Merawang Bangka & - & 23,9 \\
4 & Aliran sungai ke Kolong Merawang Bangka & - & - \\
5 & Merawang Bangka & 1090,6 & 0,9 \\
6 & Aliran sungai ke Kolong Pedindang Pangkalpinang & - & 18,4 \\
7 & Pedindang Pangkalpinang & - & - \\
8 & Aliran sungai ke Retensi Kacang Pedang 1 Pangkalpinang & - & 31,6 \\
9 & Aliran sungai ke Kolong Retensi Kacang Pedang 2 Pangkalpinang & 119,5 & 23,5 \\
10 & Retensi Kacang Pedang Pangkalpinang & - & - \\
\hline \hline
\end{tabular}

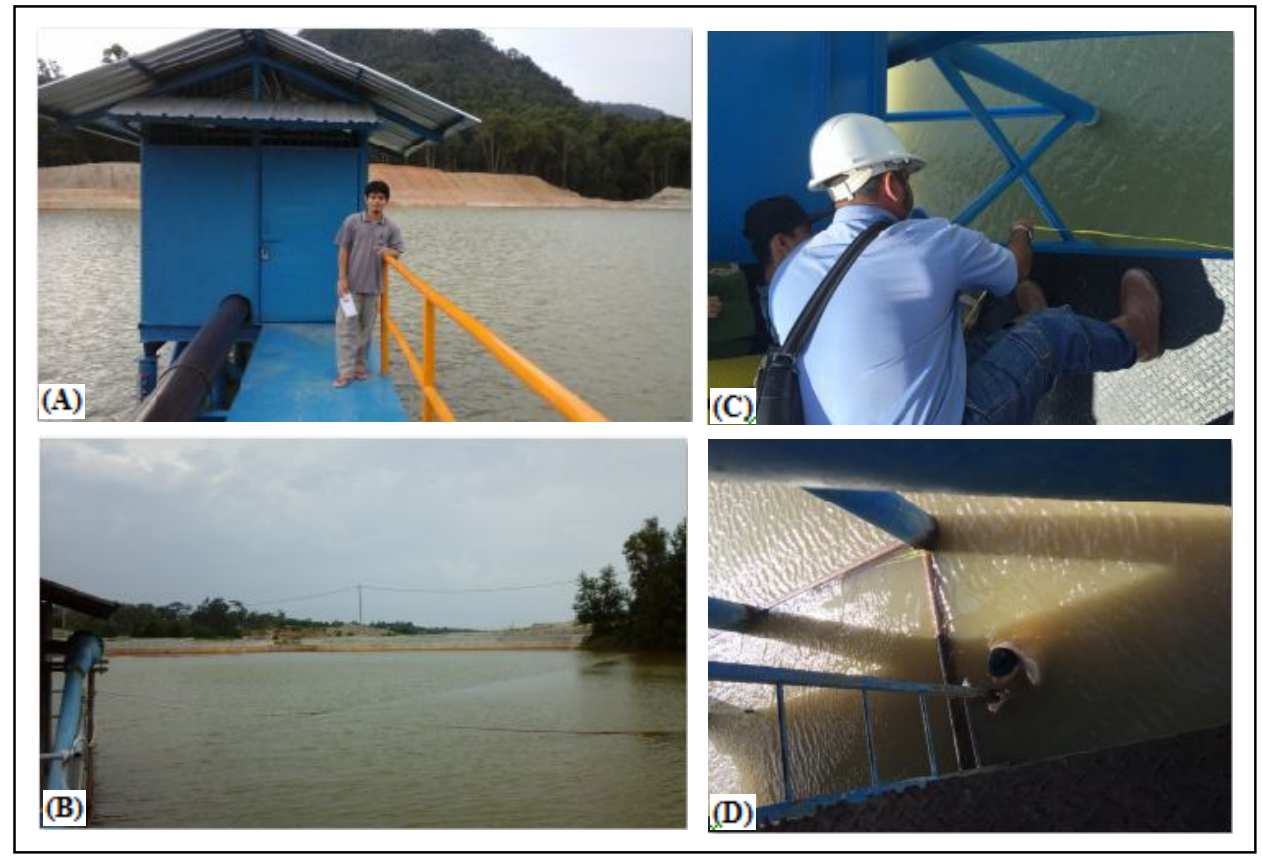

Gambar 2. Foto: (A) Kolong Argotirto, (B) Kolong Menjelang, (C dan D) Pengambilan perconto sedimen pada kolong Merawang dan Pedindang

\section{Kesimpulan}

Berdasarkan hasil penelitian yang telah dilakukan dapat disimpulkan :

1. Unsur REE berupa serium (Ce) dan yittrium (Y) yang terdapat di dalam endapan sedimen pada berbagai kolong di Pulau Bangka memiliki komposisi beragam. Unsur REE Ce hanya dijumpai pada beberapa perconto sedimen kolong sedangkan $Y$ ditemukan pada hampir semua perconto sedimen.

2. Sebaran lateral unsur $\mathrm{Ce}$ dan $\mathrm{Y}$ pada kolong dapat diperkirakan bersifat heterogen. Walaupun masih diperlukan penelitian lanjutan/detail untuk melihat konsistensi sebaran tersebut

\section{Daftar Pustaka}

Aleva, G.J.J. 1985. Indonesian Fluvial Cassiterite Placers and Their Genetic Environment. Journal of Geological Society, London, Vol. 142, p. 815-836.

Barber, A.J., Crow, M.J. and De Smet, M.E.M. 2005. Tectonic Evolution. In Barber, A.J., Crow, M. J. and Milsom, J. S. (ed.) Sumatra: Geology, Resources and Tectonic Evolution. Geological Society Memoir, No. 31.

Castor, S. B. and Hendrick J.B. 2006. Rare Earth Elements in Kogel et al. (ed.) Industrial Minerals and Rocks. $7^{\text {th }}$ edition, Society for Mining, Metalurgy and Exploration, Inc., p.769792. 
Cobbing, E.J. (2005) Granite. in Barber, A.J.,Crow, M.J. and Milsom,J.S. (ed.) Sumatra: Geology, Resources and Tectonic Evolution. Geological Society Memoir, No. 31. Page 54 -62.

Crow, M.J. and Barber, A.J. 2005. Simplified Geological Map of Sumatra. In Barber, A.J., Crow, M.J. and Milsom, J.S. (ed.) Sumatra : Geology, Resources and Tectonic Evolution. Geological Society Memoir, No. 31.

Hannigan, R., Dorval, E., Jones, C. 2010. The Rare Earth Element Chemistry of Estuarine Surface Sediments in The Chesapeake Bay. Journal of Chemical Geology 272. p. 20-30.

Hamzah, Z., Monica, N.A. and Saat, Ahmad. 2009. Determination of Heavy Minerals in Amang from Kampung Gajah Ex-Mining Area. The Malaysian Journal of Analytical Sciences, Vol. 13 No.2. p. 194-203.

Jayaprakash, C., Sajeev, R. and Kumar, Anil A. 2016. Distribution of Rare Earth Elements in The Inner Shelf Sediments, off The Southwest Coast oh India. Indian Journal of Geo Marine Sciences, Vol. 45 No. 12. pp. 1623-1630.

Katili, J.A. 1967. Structure and Age of The Indonesian Tin Belt With Special Reference to Bangka. Tectonophysics, Vol 4 (4-6), p. 403418. Nedherlands.

Ko, U. Ko. 1986. Preliminary Synthesis of the Geology of Bangka Island, Indonesia.
Geological Society of Malaysia Bulletin, 20. p. 81-96.

Krahulec, Ken. 2011. Rare Earth Element Prospects and Occurences in Utah. Utah Departement of Natural Resources, Utah Geological Survey. Utah Trust Land

Mangga, A.S. dan Djamal, B. (1994) Peta Geologi Lembar Bangka Utara dan Bangka Selatan, Sumatra. Pusat Penelitian dan Pengembangan Geologi, Bandung.

Margono, U., Supandjono, R.J.B. dan Partoyo, E. (1995) Peta Geologi Lembar Bangka Selatan, Sumatra. Pusat Penelitian dan Pengembangan Geologi, Bandung.

McLemore, V. T., 2012. Rare Earth Elements Deposits in New Mexico. Proceeding of the $48^{\text {th }}$ Annual Forum in the Geology of Industrial Minerals. Arizona. P.1-16.

Rodrigueaz, A. J. M., Martinez, A.S., Ordonez, V.R.M., Martinez, A.S. and Rueda, F.B. 2013. Patterns of Rare Earth Elements in Sediments as Tracers in a Fluvial System Influenced by a Gold Mine, El Triunfo, BCS, Mexiko. Procedia Earth and Planetary Science, p. 558 - 561.

Sujitno, Sutedjo (2015) Sejarah Penambangan Timah Indonesia: Catatan Sejarah Pertimahan s/d 2012. Penerbit PT Bina Prestasi Insani, Jakarta.

Van Bemmelen, R.W. 1970. The Geology of Indonesia. General Geology Volume I A. Martinus Nighoff, The Hague, Netherland. 